\title{
IDENTIDADES EM PRÁTICAS DE LETRAMENTOS COM TECNOLOGIAS DIGITAIS: A COMUNICAÇÃO ORAL GAMIFICADA EM UM CLUBE DE INGLÊS
}

\section{IDENTITIES IN LITERACY PRACTICES WITH DIGITAL TECHNOLOGIES: GAMIFIED ORAL COMMUNICATION IN AN ENGLISH CLUB}

\author{
Adriana Fischer ${ }^{1}$, Mariana Vicentini ${ }^{2}$
}

\begin{abstract}
RESUMO: Este estudo busca compreender relações entre comunicação oral gamificada e as identidades de estudantes em práticas de letramentos escolares na aprendizagem de inglês. Fundamentados na perspectiva sociocultural dos letramentos, discutimos dados gerados junto a três membros de um Clube de inglês, durante a elaboração de uma comunicação oral com o apoio da gamificação e das Tecnologias Digitais (TD). Os dados em análise são advindos da atividade de comunicação oral elaborada pelos membros e de um grupo focal realizado ao final do semestre do Clube. Os resultados indicam que a gamificação permitiu aos membros evidenciarem formas singulares de se posicionar em relação à leitura, à escrita e diferentes formas de ser, agir e elaborar sentidos no contexto escolar. Entretanto, o estudo também revela a necessidade de que às TD e ao uso da gamificação sejam atreladas práticas de aprendizagem que tenham sentido para os participantes.
\end{abstract}

PALAVRAS-CHAVE: identidades; comunicação oral; gamificação; tecnologias digitais.

ABSTRACT: This study seeks to understand the relationship between gamified oral communication and students' identities in school literacy practices when learning English. Based on the sociocultural perspective of the literacies, we discussed data generated with three subjects, in an English Club, during the elaboration of an oral communication with the support of gamification and Digital Technologies (DT). The data under analysis comes from the oral communication activity developed by the subjects and a focus group held at the end of the semester of the Club. The results indicate the gamification allowed the members to show singular ways of positioning themselves in relation to reading, writing and different ways of being, acting and meaning making in the school context. However, the study also reveals the need to link DT and the use of gamification to learning practices that make sense for the participants.

KEYWORDS: identities; oral communication; gamification; digital technologies.

\footnotetext{
${ }^{1}$ Doutora em Linguística Aplicada pela Universidade Federal de Santa Catarina. Docente do Programa de PósGraduação em Educação da Universidade Regional de Blumenau.

${ }^{2}$ Doutoranda no Programa de Pós-Graduação em Educação na Universidade Regional de Blumenau.
} 


\section{Diálogos Iniciais}

A discussão apresentada neste artigo encontra suporte no que um grupo de estudiosos (STREET, 2003, 2008; BARTON; HAMILTON, 2000) denominou Novos Estudos dos Letramentos (NEL), proposta fundada para contrastar os estudos anteriores da área, antes centrados nas habilidades de escrita de indivíduos e sua mente, sem considerar seu contexto de interação e práticas sociais (VIANNA et al. 2016). A proposta dos NEL é a de que leitura, escrita e oralidade não são neutras e independentes dos processos históricos, sociais e culturais. Ao contrário, os letramentos são compreendidos como práticas sociais, dependentes dos contextos sociais nos quais a língua se inscreve.

Entretanto, há de se problematizar que ainda resiste, no contexto escolar, uma perspectiva curricular dos letramentos (KLEIMAN, 2010) em que as práticas de letramentos (BARTON; HAMILTON, 2000; STREET, 2003) ali promovidas, por vezes, não consideram as identidades em torno do contexto escolar. Nesse sentido, é constante o desafio de fomentar uma perspectiva escolar de letramentos (KLEIMAN, 2010) que recontextualize, de maneira crítica, práticas com as quais os estudantes convivem diariamente em diversas esferas de atividade. Nessa vertente, considera-se que a disseminação de TD mantém relação direta com esta problematização, visto que seu avanço é perceptível, em diferentes escalas e distintos espaços sociais, incorporando-se às práticas de letramentos de diferentes sujeitos, inclusive àqueles em idade escolar.

Contudo, é relevante fomentar o conceito de tecnologia como construção social, produção, aplicação e apropriação das práticas, saberes e conhecimentos. Nesse sentido, as TD são concebidas, em nossas discussões, como mecanismos que ressignificam e refratam (BAKHTIN; VOLOCHINÓV, 2006) os letramentos, por oferecerem uma diversidade de possibilidades para a mudança nas práticas desenvolvidas no contexto escolar (GOURLAY; HAMILTON; LEA, 2014) e da valorização de letramentos vernaculares de diferentes sujeitos. De acordo com Leffa, Costa e Beviláquia (2017), é quase palpável a dificuldade da instituição escolar se conectar com o mundo vivido por jovens que, atualmente, crescem em meio à cibercultura. Grande parte desse distanciamento e da transformação no perfil dos estudantes se justifica pela influência que as TD exercem nas esferas que esses sujeitos convivem, já que, de acordo com diversos estudos (LEA; HAMILTON; GOURLAY, 2014; GEE, 2015) compreende-se que as TD são capazes de provocar mudanças profundas na cultura, na comunicação e interação, na forma de organização social e na própria aprendizagem em 
determinado grupo ou comunidade.

Considerando as discussões tecidas até o momento em torno da forma como as TD podem ser concebidas e sobre seus usos em práticas de letramentos, é relevante destacar que, ao considerar que os letramentos sempre se desenvolvem a partir de aprendizagens culturais e são adquiridos como parte das identidades das pessoas (GEE, 2000), a compreensão sobre formas como os membros deste estudo constituem suas identidades em práticas de letramentos fora do contexto escolar pode dar indícios dos modos como essas identidades refletem em sua inserção em práticas de letramentos escolares na aprendizagem da L2. ${ }^{3}$

Ao fazer uso do conceito de identidades, apoiamo-nos em definições a partir de um olhar sócio-histórico. Nesse sentido, as identidades não são fixas e estáveis, pelo contrário, estão sempre se refazendo, em um processo de mutação que ganha forma nas tensões e fricções da relação com o outro, em diferentes tempos e espaços (HALL, 2006; NORTON, 2010).

Assim, depreendemos que as distintas identidades de sujeitos envolvidos em práticas de letramentos são flexíveis (NORTON, 2010) e circulam facilmente por diferentes contextos, sem que uma identidade se desvincule da outra nesses percursos. Portanto, a inserção de sujeitos em diferentes práticas de letramentos, em variados contextos, está predisposta a conflitos, já que demanda que sujeitos assumam determinadas identidades de forma mais evidente do que outras. Apesar da noção de que esse conflito é característico dos letramentos, posicionamo-nos no sentido de que agências de letramentos, como a escola, "não podem mais ser compreendidos como fontes imanentes de normas e restrições, sem que se leve em conta o fato de que abarcam diversas identidades encadeadas na forma de sujeitos" (BUZATO, 2014, p. 52).

A problemática em torno dos conflitos entre a inserção em diferentes práticas de letramentos e as distintas identidades de sujeitos se fez presente no contexto deste estudo, um Clube de Inglês. O Clube se constitui como uma atividade extracurricular oferecida aos estudantes de um primeiro ano do Ensino Médio, de uma escola particular localizada no interior do estado de Santa Catarina. Uma das problemáticas enfrentadas no Clube, que será especificada de forma mais profunda no capítulo metodológico, foi a relação dos membros com a abordagem teórico-metodológica proposta, inicialmente, durante os encontros, centrada em atividades indicadas em um determinado material didático. Tal relação de distanciamento

\footnotetext{
${ }^{3}$ O termo L2 será utilizado a fim de evitar a repetição dos termos "inglês", "segunda língua”, "língua estrangeira" e "língua inglesa". Optamos pela quase totalidade de uso do termo L2 para nos referirmos a essas nomenclaturas.
} 
com a proposta se deu, pois, grande parte do conhecimento em torno da L2 que os membros possuíam era advinda de interações com nativos ${ }^{4}$ do idioma em games $^{5}$ na modalidade multijogador e com a comunidade (WENGER, 2004) dos games. Entretanto, por meio da negociação com os clubistas, com vistas a considerar os indícios das identidades de aprendizes do idioma trazidos ao Clube de Inglês, foi sugerido o uso da gamificação, definida por Deterding et al. (2011), como o uso de características dos jogos em contexto não jogo.

A discussão em torno da abordagem teórico-metdológica utilizada no Clube, na relação com o uso da gamificação, nos orienta a problematizar questões referentes ao ensino da L2 em práticas de letramentos escolares, com destaque ao papel do professor nesse percurso, pois, ao passo em que concebemos o uso dos princípios dos jogos como uma possível ferramenta de aprendizagem, destacamos que deslegitimar a escola, o ensino das línguas, em valorização somente aos jogos e às tecnologias digitais (TD) em uso pelos estudantes, é uma ação infundada. Assim, reitera-se a importância do papel da escola nesse cenário como uma instituição que abarca múltiplos letramentos e como um lugar para onde estudantes trazem consigo diferentes experiências de vida, de modo que eles acabam aprendendo e refletindo de maneiras diferentes (KLEIMAN, 2010).

Definimos como objetivo norteador deste estudo compreender relações entre comunicação oral gamificada e as identidades de estudantes em práticas de letramentos escolares na aprendizagem de inglês. Para responder a este objetivo, o presente artigo está organizado em mais três seções: a segunda, 'percurso metodológico' que explica os percursos de geração de dados e indica as regularidades de análise que orientam nossas discussões; a terceira, “Tu podia botar muito mais a tua identidade': discussões de dados no Clube de inglês a partir da comunicação oral gamificada' discute os dados em torno das identidades dos membros do Clube em práticas de letramentos com gamificação e, por fim, na seção '(In)acabamentos' trazemos as principais considerações em torno do desenvolvimento deste estudo.

\section{Percurso metodológico}

Este artigo apresenta dados inéditos, advindos de uma pesquisa longitudinal realizada

\footnotetext{
${ }^{4}$ A concepção adotada para este termo é a de que é falante nativo de inglês quem tem inglês como primeira língua, e não-nativo quem o tem como outra língua que não a primeira - sem as conotações imperialistas a que o termo costuma ser associado (JORDÃO, 2014).

5 Ao mencionarmos os termos "games" "e "jogos", estamos sempre nos referindo àqueles online, na modalidade multijogador e com interações pelo uso do inglês.
} 
durante os anos de 2018 e 2019 e que receberam um enfoque, essencialmente, qualitativo (BOGDAN; BIKLEN, 1994). Conforme mencionado na seção anterior, o contexto de realização da pesquisa foi um Clube de Inglês, atividade extracurricular oferecida aos estudantes do primeiro ano do Ensino Médio, de uma escola particular localizada no interior do estado de Santa Catarina. Dividido entre os níveis, Básico (Intro), Pré-intermediário (1A) e intermediário (2A), selecionamos, para participar deste estudo, três clubistas do nível 2A: Taro e Dante, ambos com 15 anos e Raven, de 16 anos.

As aulas do Clube de Inglês, inicialmente, eram realizadas na própria sala de aula do Ensino Médio, no contraturno, a partir de um material comercial impresso com foco no desenvolvimento das quatro habilidades da língua: ler, falar, ouvir e escrever. Por conta da abordagem teórico-metodológica adotada durante os encontros, havia indícios de certa resistência (NORTON, 2013) por parte dos estudantes, nas práticas de letramentos em L2 do Clube. Apesar disso, quando se sentiam motivados ${ }^{6}$, os membros conseguiam interagir durante a aula usando, praticamente, apenas a L2, afirmando terem adquirido aquele nível de proficiência por conta de suas interações em jogos e com a comunidade em torno dos games.

No Clube de Inglês, eram recorrentes, ainda, indícios de identidades subversivas (CANAGARAJAH, 2004) por parte dos membros quando, constantemente, sugeriam à docente a abordagem de temáticas que não eram as propostas pelo material utilizado nos encontros do Clube, pela sugestão de vídeos por parte dos membros ou pela presença de artefatos (BARTLETT, 2013) tecnológicos durante as práticas de letramentos do Clube. No contexto de sala de aula, esses espaços seguros criados pelos estudantes servem como locais de construção de suas identidades, permitindo que negociem as tensões que encontram como membros de diversas comunidades.

Com vistas a considerar elementos das identidades dos clubistas, para que a aprendizagem da L2 no Clube de Inglês passasse a ser mais significativa, a partir do diálogo com os membros, houve a opção metodológica pelo uso da gamificação, com o apoio da plataforma Classcraft ${ }^{7}$, e de TD disponíveis na escola, como computadores e os celulares dos membros. O Classcraft possibilita a criação e gamificação de atividades, simulando um jogo role-playing $(R P G)$ online gratuito e permite aos professores e aos estudantes jogarem juntos na sala de aula, incorporando três distintos personagens: Mago, Guerreiro e Curandeiro.

\footnotetext{
${ }^{6}$ Em virtude da utilização, neste artigo, dos estudos de Norton (2010), destacamos que, para a autora o conceito de motivação, muitas vezes, concebe os estudantes de línguas a ideia de personalidades muito semelhantes, as quais a autora define como históricas. Entretanto, o conceito de investimento concebe o estudante como alguém com identidades plurais, que se transformam no tempo e no espaço e que se constroem nas interações sociais. 7 www.classcraft.com
} 
Além disso, é relevante dar destaque ao fato de que, assim como a abordagem metodológica, a abordagem teórica também passou a ser definida a partir da negociação entre a docente do Clube de inglês e os membros. Foi a partir de uma proposta lançada pelos membros, com base em suas necessidades de usos da L2, que surgiu a atividade de comunicação oral gamificada, adaptada, por eles, a partir de uma pequena atividade do material do Clube.

A meta estabelecida para o desenvolvimento da atividade com comunicação oral a partir da negociação entre professora e membros foi 'discutir os modos como as Tecnologias Digitais integram nossas rotinas diariamente'. Para isso, a missão dada aos membros envolveu os seguintes elementos:

Figura 1 - Orientações aos membros no Classcraft

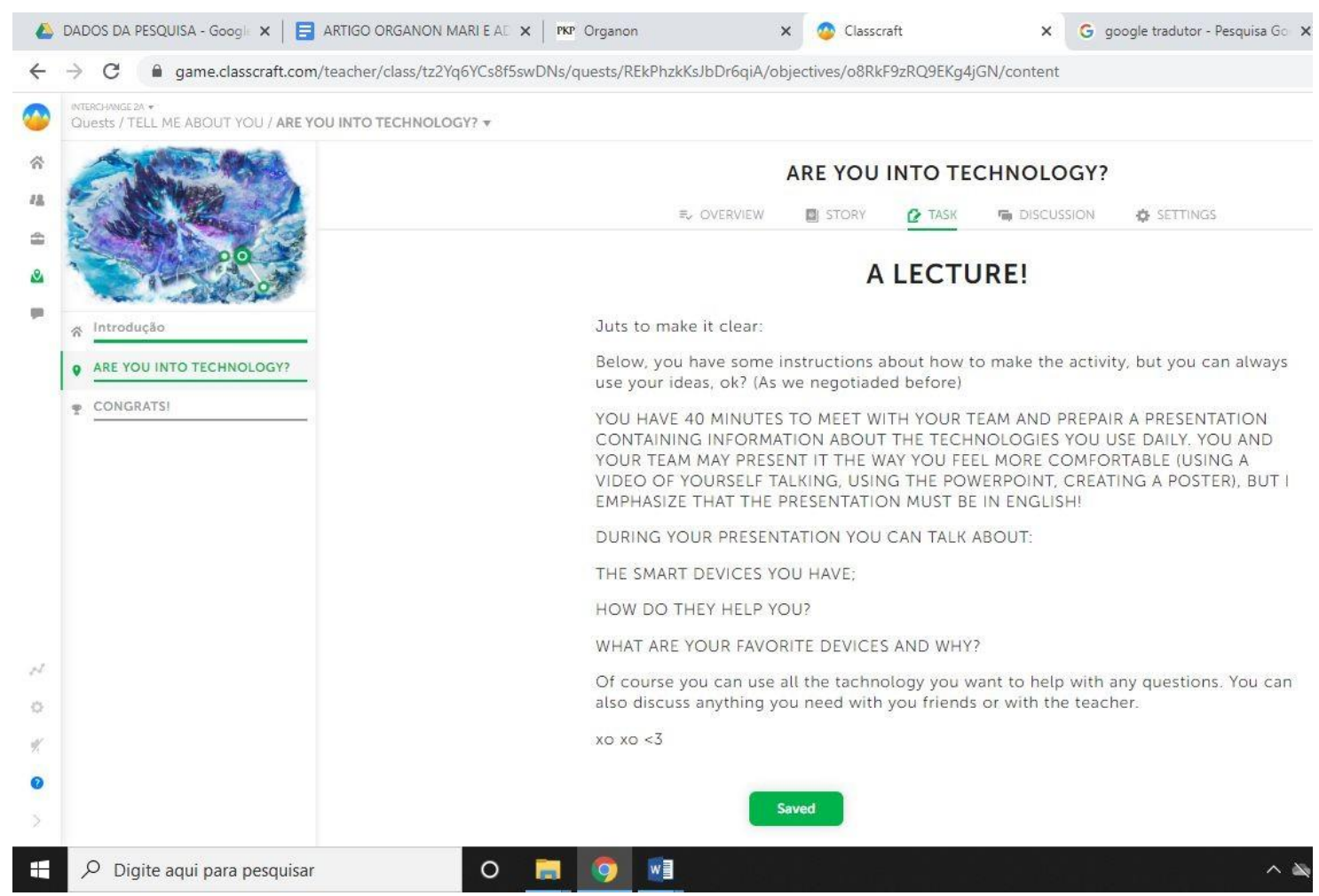

Fonte: dados da pesquisa (2018)

No Classcraft, pode-se optar por dar aos jogadores um valor específico em pontos pela mera conclusão de uma atividade. As principais pontuações na plataforma são: a) Health Points (HP): pontos que o jogador precisa para se manter ativo no jogo. Podem aumentar ou diminuir no decorrer da aula, de acordo com o desenvolvimento das atividades; b) Experience 
Points (XP): pontos dados aos jogadores de acordo com predefinições definidas entre os membtos e docente antes do início das missões; c) Golden Points (GP): pontos que os jogadores recebem quando sobem de nível. Podem ser convertidos em elementos para a personalização dos avatares.

As pontuações na atividade com comunicação oral funcionaram da seguinte forma: a) 500 XP pela discussão em grupo e elaboração da apresentação; e b) 1000 XP pela apresentação da comunicação oral. Cada membro receberia essas pontuações pela simples conclusão da tarefa pela equipe, de acordo com as negociações definidas entre clubistas e a docente, na expectativa, de que os membros não elaborassem a atividade apenas para fins de receber um prêmio, mas para que compreendessem que sua inserção nessa prática de letramentos, em L2, poderia ocorrer de forma menos conflituosa (STREET, 2003), a partir do apoio de artefatos, colegas, professora e do respeito às suas identidades. Além das pontuações mencionadas acima, foram estabelecidas regras para o desenvolvimento da comunicação oral, que poderiam fazer com que os jogadores recebessem ou perdessem uma determinada quantia de pontos, conforme demonstrado a seguir:

Figura 2 - Pontuações negociadas para a atividade de comunicação oral Fonte: elaborado pelos pesquisadores

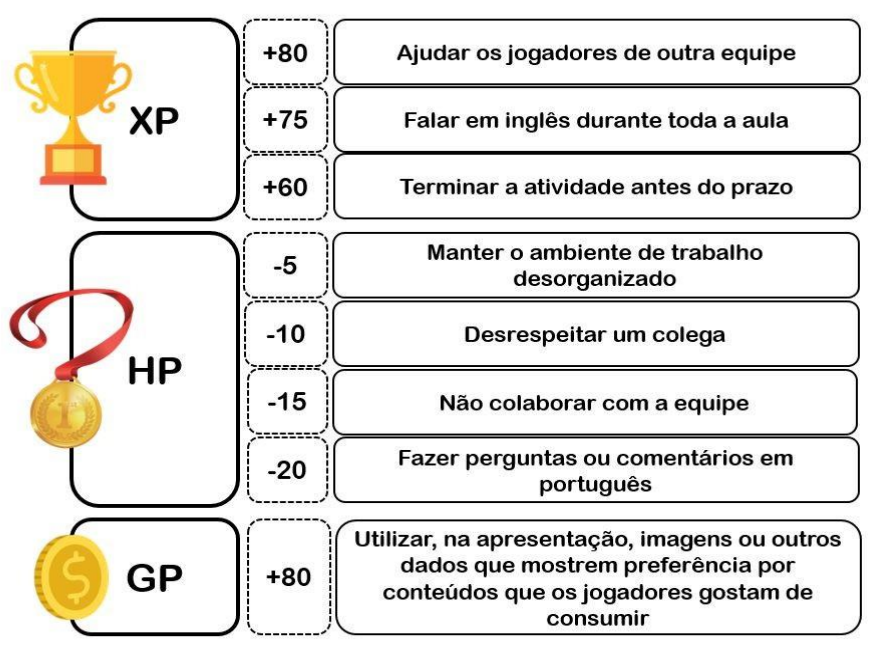

* ○

Todas as regras foram definidas coletivamente entre a professora e os membros ao início da atividade. Ao final de cada aula as regras eram novamente projetadas à turma e, coletivamente, tomava-se a decisão de quantos pontos cada equipe iria receber ou perder. 
Com base na pontuação final de cada aula, os integrantes de cada equipe recebiam as premiações, no Classcraft, denominadas de poderes. Os poderes negociados entre a professora e os jogadores para a atividade de comunicação oral foram: a) Mago: Pode transferir 3000 GP para um colega de equipe; b) Guerreiro: pode escolher a trilha sonora do próximo encontro no Clube; c) Curandeiro: dá aos integrantes de todas as equipes $50 \mathrm{HP}$. Destaca-se que todas as missões, regras e premiações definidas durante as atividades gamificadas do Clube de Inglês foram pensadas de forma a promover maior investimento (NORTON, 2013) na aprendizagem da L2 por parte dos membros. Todos os elementos da gamificação, em destaque nessa atividade, beneficiam os integrantes do Clube de forma geral e não apenas uma equipe ou um membro da equipe.

Considerando a opção dos membros deste estudo pela não gravação em áudio ou vídeo da apresentação oral e com vistas a manter a ética da pesquisa na relação com esses membros, selecionamos como dados, para orientar as discussões: a) a apresentação elaborada pelos membros para a atividade de comunicação oral e b) dados advindos de um grupo focal realizado com os membros ao final do semestre do Clube de Inglês, em que se posicionam acerca do desenvolvimento da comunicação oral gamificada.

Dos dados apresentados, emergem como regularidades, principalmente a relação dos membros com as orientações nas práticas de letramentos, com os artefatos culturais, com a gamificação e com os usos da L2. Essas regularidades são analisadas na seção a seguir, pelo enfoque dos Novos Estudos dos Letramentos (STREET, 2003; BARTON; HAMILTON, 2000).

\section{'Tu podia botar muito mais a tua identidade': discussões de dados no Clube de inglês a partir da comunicação oral gamificada.}

Como forma de dar início às análises dos dados gerados no Clube de Inglês, destacamos o que discutem Lea, Hamilton e Gourlay (2014), ao citar que diferentes letramentos existem e precisam ser reconhecidos ao invés de ser privilegiado um único padrão universal que normaliza um conjunto de práticas. A partir dessa perspectiva, os NEL afirmam a natureza situada das práticas com TD. A proposta levantada pelos autores é relevante, no contexto deste estudo, pois as TD assumem um papel de destaque nas práticas de letramentos dos membros dessa pesquisa, em diferentes contextos e este fato pode ser decisivo para a construção de sentidos em práticas de letramentos escolares das quais participam. 
Nessa perspectiva, consideramos que o uso de elementos como a gamificação e de TD, no Clube de Inglês, para a inserção desses clubistas em diferentes Discursos é mais significativa, permitindo que se posicionem como insiders (GEE, 2001) em práticas de letramentos. Em outras palavras, os conhecimentos dos clubistas acerca dos usos das TD e do funcionamento dos games na relação com novos Discursos em que estão sendo inseridos pode conferir a eles a sensação de controle da situação na aprendizagem da L2, decorrente do uso de suas habilidades em diferentes práticas de letramentos, validando a afirmação de Gee (2001, p. 137) de que "significado na linguagem está vinculado às experiências das pessoas no mundo material e social".

Além disso, posicionamo-nos no sentido de que, para que se desenvolva um percurso de aprendizagem significativa dentro do Clube de Inglês, não é suficiente apenas a instrução formal para que os membros se tornem insiders naquele contexto, mas sua inserção nesse contexto onde possa participar efetivamente das interações sociais (FISCHER, 2007). Dessa forma, segundo (FISCHER, 2011) é "decisivo é compreender como um sujeito se torna letrado, o que aprende e como aprende o que é importante, essencial em contextos e práticas de leitura, escrita e oralidade, e como é reconhecido seu potencial de letramento" (p. 573). Não considerar os meios como estudantes se inserem em práticas de letramentos implica em correr o risco de fazer com que esses membros não se sintam integrados às práticas escolares, às quais são chamados a se integrar, ou ainda, pode fazer com que esses clubistas acreditem precisar assumir um papel dentro da escola, que não os representa. Essa problemática pode resultar em conflitos identitários como demonstrado no excerto (1), quando os membros são questionados acerca de como podem se posicionar como aprendizes de um idioma no Clube de Inglês:

(1)

Raven: é, e quem disse que eu sou um aluno, o que é um aluno?

Taro: a gente é, nós somos seres humanos, a gente tem nossas escolhas, nossas vontades [...] (Grupo focal, 2018).

A problematização feita pelos membros em (1), encontra apoio no que pontua Zavala (2010), acerca de como estudantes concebem a si mesmos, perante às novas práticas de letramentos em que são inseridos, ao ingressarem em contextos de ensino que, por vezes, não consideram suas identidades. Para ela, novos letramentos são concebidos por estudantes “como uma espécie de jogo" (ZAVALA, 2010, p. 74), que demanda assumirem uma identidade na qual não se reconhecem, ou, como cita a autora, "que não sou eu" (ZAVALA, 
2010, p. 74). Esse contexto indica que as tensões que emergem entre estudantes e professores referentes à inserção daqueles em práticas de letramentos escolares não se relaciona apenas a questões gramaticais ou textuais, mas a aspectos relacionados com a identidade desses membros no que concerne às formas de aprender, como é levantado por eles em (2):

(2)

Raven: [...] tipo, não faz sentido cobrarem isso da gente, 'a seja um aluno', 'a porque os professores estão reclamando', mas tá, olhar pra um quadro, um monte de anotação, tudo feito com canetão que tu vai ali, copia [...] também não interessa mais.

Taro: [...] eu não aprendo copiando.

Dante: tem gente que não aprende assim copiando, tem gente que aprende prestando atenção, tipo, tu tem que dar a liberdade pro aluno, [...]'se você aprende melhor copiando, copia, se você aprende melhor prestando atenção você presta atenção’ (Grupo focal, 2018).

Em relação ao excerto (2), Gee (2015) discute que a aquisição dos letramentos constitui a apropriação de práticas discursivas orais e escritas que se desenvolvem como parte de como pessoas dão sentido a sua experiência no processo de sua socialização. Por isso, na aquisição de práticas discursivas, não só adquirimos certas habilidades como também certos valores, atitudes, motivações, perspectivas e maneiras de interagir, todas as quais, de acordo com o apontado por Gee (2015), acabam sendo mais importantes que as habilidades para obter ganhos na escola. Esta é a razão pela qual os letramentos não estão apenas vinculados a formas de pensar, mas também a formas de sentir e valorizar em relação a si mesmo (GEE, 2005). Pode-se relacionar esta discussão de Gee com as problemáticas levantadas pelos membros em (2), quando questionam o fato de a escola exigir deles uma postura de aluno, referindo-se a um modelo arcaico de estudante, com uma rotina de estudos que, em partes, já não é mais relacionada às quais estão habituados. Conforme previsto pelas dimensões socioculturais dos letramentos (BARTON; HAMILTON, 2000), grande parte das práticas de letramentos desses membros são estruturadas e sustentadas por instituições específicas, permeadas por relações de poder. Porém, não se pode desconsiderar que as formas como osmembros constroem sentidos a partir do que é estudado na escola, relaciona-se com objetivos sociais e práticas culturais mais vastas, como usos de TD, vídeos, plataformas online para estudos, ao invés do uso do caderno como ferramenta para anotações e consulta.

Como consequência desses conflitos relacionados às formas de aprender, é comum que os estudantes resistam ou não se comprometam com o que a escola demanda, por razões que têm a ver, com seu "custo pessoal", como denomina Zavala (2010, p. 81). Em outras palavras, esses modelos de estudos não têm relação com as identidades desses membros, 
fazendo com que não se sintam eles mesmos com abordagens desse tipo. É interessante perceber, a partir dos depoimentos em (1) e (2), que a escola parece estar distante de práticas cotidianas na relação com a leitura e escrita para a aprendizagem da L2. Entretanto, conforme Kleiman (2010), apesar de não considerar que o ensino de formas raras e arcaicas não deveria ser importante na escola, não se pode incentivar um preconceito contra o domínio dessas formas. Não se trata de achar agora que aqueles que utilizam formas mais antigas é que estão errados. Trata-se apenas de não haver preconceito contra os usos de artefatos e de formas linguísticas mais recentes (KLEIMAN, 2010).

As figuras 3 e 4 são parte componente da apresentação elaborada pelos membros e, conforme mencionado no parágrafo acima, deixam emergir posicionamentos de suas identidades, além do uso de elementos multissemióticos advindos da esfera não escolar:

Figura 3 - Apresentação elaborada pelos membros Fonte: dados da pesquisa (2018)

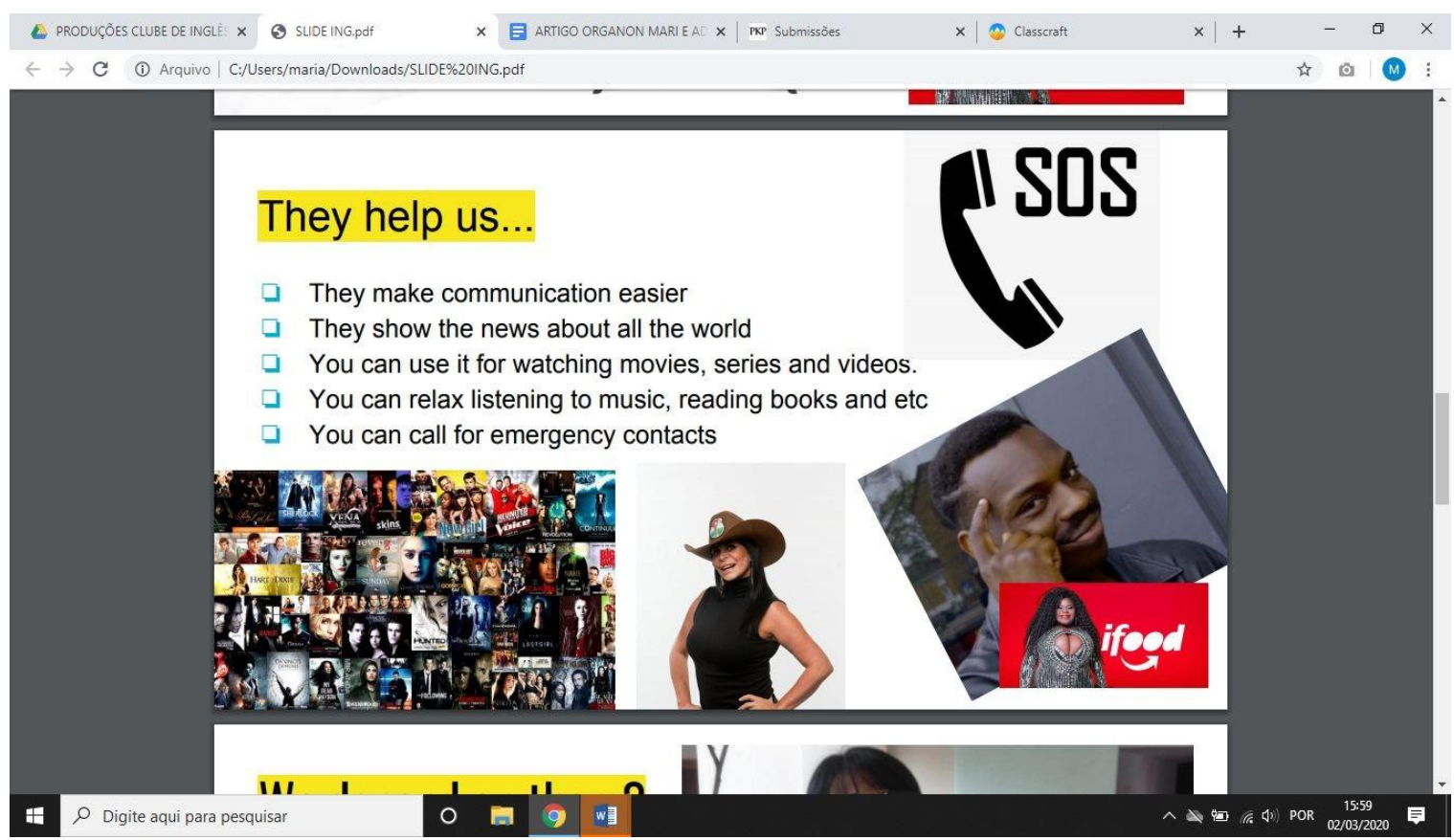


Figura 4 - Apresentação elaborada pelos membros (2) Fonte: dados da pesquisa (2018)

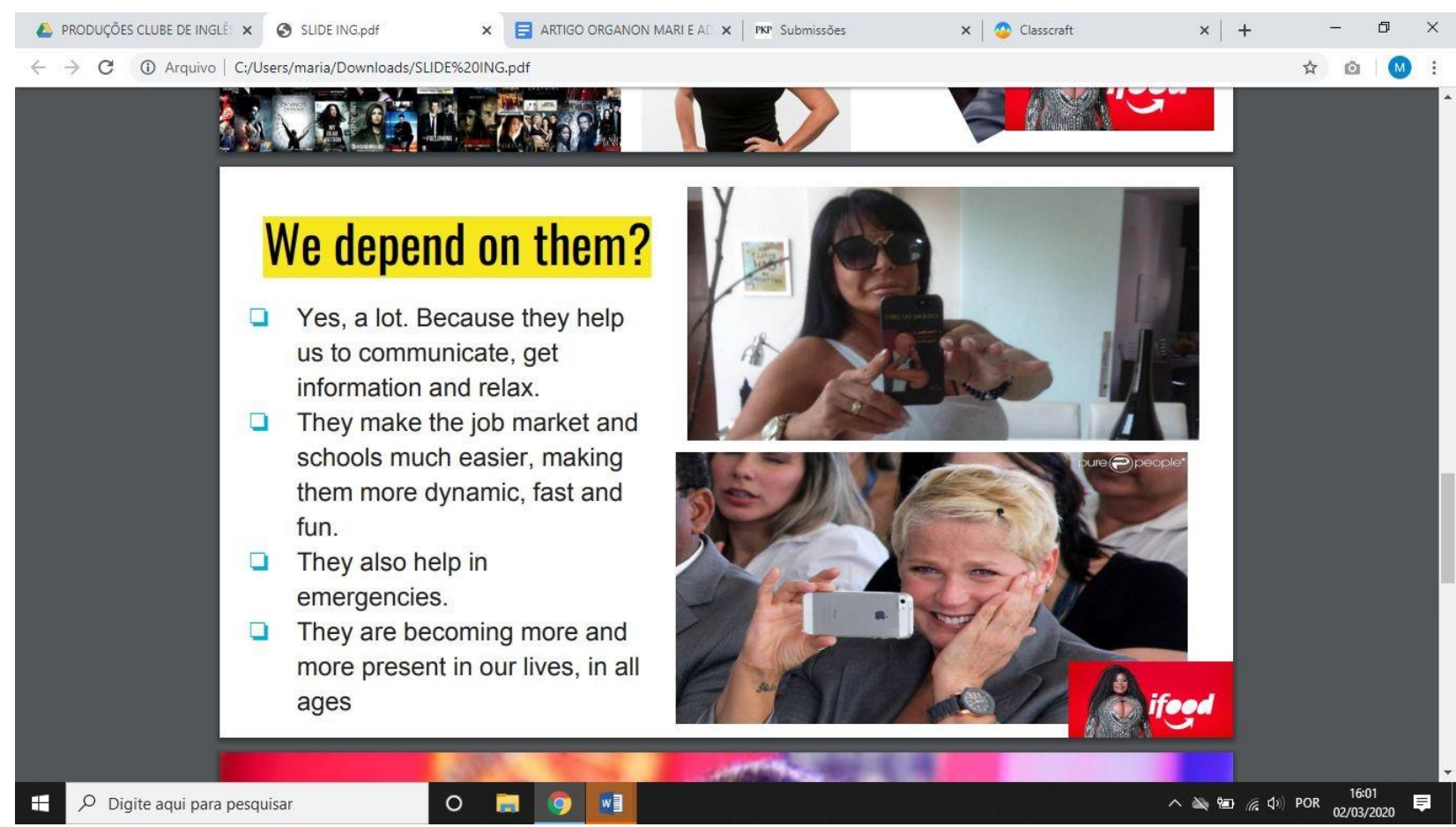

A partir da análise das imagens percebe-se, essencialmente, a manifestação do posicionamento autoral dos membros dentro da atividade. Isso se evidencia, principalmente quando a atividade é comparada à proposta (Figura 1) apresentada aos membros via Classcraft. Na figura 3, os membros trazem para discussão elementos propostos na atividade, entretanto, na figura 4, tomam a liberdade de levantar discussões em torno de um tópico de seu interesse, não integrante das orientações no Classcraft: 'a dependência pelas tecnologias digitais'. Ademais, as sentenças desenvolvidas pelos membros deixam emergir indícios dos modos como as TD estão incorporadas as suas rotinas, dados que podem servir como impulso para novas práticas a serem propostas no Clube.

Além disso, há na apresentação elaborada pelos membros, a presença de imagens que circulam na internet em forma de memes ${ }^{8}$. Isso pode indicar, de certa forma, os tipos de conteúdo com os quais esses estudantes se envolvem em outras esferas que não a escolar, fornecendo, também, indícios de suas identidades. Ainda, pode-se compreender que os sentidos construídos por esses estudantes a partir dessa atividade é a de que a apresentação não necessariamente precisaria ser feita sob uma perspectiva normativa, o que lhes permitiu conferir um tom irônico e descontraído à apresentação. Esses dados vão ao encontro do que

\footnotetext{
${ }^{8}$ Termo que indica imitação. É utilizado na internet para se referir à viralização de um conteúdo.
} 
discute Norton (2013), ao afirmar que identidades são influenciadas por práticas comuns a agências como lares, escolas e locais de trabalho, além de recursos disponíveis, sejam eles simbólicos ou materiais. Entretanto, as condições estruturais e os contextos sociais não determinam inteiramente o aprendizado ou o uso de idiomas. Será por meio da agência humana, que os estudantes de uma L2 irão se esforçar para falar a partir de uma posição de identidade, podendo ser capazes de reformular seu relacionamento com os outros e reivindicar identidades alternativas mais poderosas para falar, ler ou escrever, melhorando a aquisição da L2 (NORTON, 2013).

Em relação às necessidades de correções existentes na atividade, a exemplo dos títulos em destaque nas figuras 5 e 6 que, conforme a gramática normativa deveriam ser: 'Do they help us?' ou 'How do they help us?' 9e 'Do we depend on them' ou 'How do we depend on them? ${ }^{\prime 10}$, todas foram encaminhadas via Classcraft e, em encontros posteriores, essas construções linguísticas serviram como ponto de partida para estudos em torno do tempo verbal 'simple present' e 'simple present with Wh questions'. ${ }^{11}$ Em relação a essa forma de correção das atividades, os membros se posicionam, em (3):

(3)

Raven: [...] quando a gente gamificou, tipo, falou errado, o feedback era diferente [...]

Taro: o foco era no processo de como a gente fazia e, como Raven falou, [...] a teacher corrigia as coisas pra gente, erros de escrita ou gramática, pelo Classcraft mesmo, sem ficar expondo. [...] e o legal era, tipo, ah, tu errou, se escreve assim, vamos usar assim da próxima vez', e pelo Classcraft. Tu ajuda o aluno, não fica só quantificando (Grupo focal, 2018).

A fala inicial de Raven, ao mencionar mudanças nas formas de se dar feedback, tem relação com as discussões de Gee (2015), ao explicar que estudantes não conseguem interpretar um grande bloco de informações se não souberem como usá-las em um contexto específico, o que prejudica seu desempenho de diversas formas em uma atividade, seja desmotivando-o, gerando insegurança, ou deixando-os confusos. Nas palavras do autor, a linguagem é efetiva e, portanto, informações devem ser fornecidas aos estudantes quando eles solicitarem ou quando puderem utilizá-las imediatamente e, caso não as compreendam, devem ter a possibilidade de retornar e ter acesso a ela até que possam interpretá-la e fazer uso dela. Isso se manifesta na gamificação do Clube de Inglês, pois o uso do feedback imediato, via Classcraft, simula o feedback que esses membros recebem em um jogo, por

\footnotetext{
9 'Eles te ajudam?' ou 'Como eles te ajudam?'.

10 'Nós dependemos delas?' ou 'Como nós dependemos delas?'

11 'presente simples' e 'presente simples com perguntas que iniciam com Wh'.
} 
exemplo, visto que é fornecido simultaneamente ao momento da apresentação e serve para orientá-los em suas tentativas de uso da L2, assistindo-o no seu desempenho, possibilitando que ele aja acima de sua competência, superando-se (LEFFA; PINTO, 2014).

É relevante dar atenção à percepção de Raven acerca do feedback a partir da gamificação na atividade com comunicação oral: "ah, tu errou, se escreve assim, vamos usar assim da próxima vez, tu ajuda o aluno, não fica só quantificando”. A fala de Raven corrobora a ideia de Leffa e Pinto (2014), pois, para esses autores, quando estudantes fazem atividades por obrigação, em grande medida, e não por se sentirem inseridos na prática, há a tendência de que não irão se mostrar interessados de receber um feedback ou de solicitar informações ao professor para a solução de possíveis dúvidas. Percebe-se, na fala do membro, a sua concepção do que envolve a prática de aprendizagem. Nessa direção, o enunciado (3) dá indícios de que, para esses membros do Clube, o feedback passou a ocorrer de forma mais amena, direcionada ao estudante e não apenas por meio da correção coletiva, como, por vezes, ocorria dentro do Clube. Há indícios, nos depoimentos dos membros, de uma valoração positiva às possibilidades de uso da L2 também de uma maneira que eles denominam como 'casual', 'funcional', conforme emerge dos excertos (4) e (5):

\section{(4)}

Taro: O nosso grupo foi o casual assim, porque a gente vai chegar lá né, pra falar com um estrangeiro, as gírias, as expressões atuais, [...] a gente não precisa saber só a forma culta, a gente tem que saber as gírias também, o jeito que a gente usa socialmente, né? (Grupo focal, 2018).

\section{(5)}

Raven: [...] quando a gente gamificou, a gente aprendeu aquilo ali inserido num contexto de outras palavras, então, tipo assim, eu acho que dessa forma se torna mais funcional e eu passei a aprender um inglês que tu vais usar definitivamente, porque tem muita coisa que a gente via antes [...] que eu não vou lá nos estados unidos me comunicar daquele jeito e eu senti que gamificando eu consegui usar a linguagem mais casual, como num jogo mesmo [...] (Grupo focal, 2018).

É relevante destacar que, além de uma valoração positiva às formas de utilizar a L2 a partir da comunicação oral gamificada, os depoimentos dos membros em (4) e (5) remetem ao que Norton (2013) denomina de comunidades imaginadas, ou seja, grupos de pessoas, não imediatamente tangíveis e acessíveis, com quem nos conectamos através do poder da imaginação, como em (4) "a gente vai chegar lá né, pra falar com um estrangeiro, as gírias, as expressões atuais" e (5) "a aprender um inglês que tu vais usar definitivamente, porque 
tem muita coisa que a gente via antes [...] que eu não vou lá nos estados unidos me comunicar daquele jeito" em que os membros afirmam a necessidade de aprender, não somente o inglês em sua forma normativa, mas aquele utilizado socialmente para que consigam se comunicar com estrangeiros. Apesar de os membros já interagirem com falantes nativos da L2 em games, as afirmações acima feitas por eles são somadas aos verbos 'vai' e 'vou', dando indícios de que os membros imaginam ou planejam o uso do idioma em um outro contexto, com nativos que ainda não conhecem. Essa discussão se afilia com o posicionamento de Norton (2013), ao inferir que apesar de interagimos com muitas comunidades cuja existência pode ser sentida concreta e diretamente, como nossas comunidades de bairro, nossos locais de trabalho, nossas instituições educacionais, essas não são as únicas comunidades às quais somos afiliados. Para Wenger (2004) a imaginação é outra fonte importante de comunidade. Norton (2013) discute que o foco nas comunidades imaginadas no aprendizado da L2 nos permite explorar como a afiliação dos alunos a essas comunidades pode afetar suas trajetórias de aprendizado. Tais comunidades incluem relacionamentos futuros que existem apenas na imaginação do aluno, bem como afiliações - como nacionalidade, por exemplo. Os membros ainda deixam emergir suas opiniões acerca de como se deu o aprendizado da L2 incorporado ao uso das TD e da gamificação:

(6)

Dante: É né, que, botar, tipo, objetivos e não os meios que você deve fazer [...] e, sim, no final você vai ter aprendido alguma coisa e, assim, tipo, o fato de você tá ali no computador epoder ter a liberdade de usar a tecnologia a teu favor é muito legal (Grupo focal, 2018).

(7)

Taro: é, e no clube com Classcraft a gente não tinha mais essa pressão de ter que ter essa postura de estudante [...] então tu podia botar mais a tua identidade aí, tipo, ah, tô fazendo esse slide e vou botar a Gretchen aqui (Grupo focal, 2018).

Os excertos (6) e (7) se relacionam com o que problematiza Gee (2015) em torno da forma como a instituição escolar tenta moldar os modos pelos quais diferentes estudantes devem alcançar objetivos propostos. Nas palavras do autor, instituições de ensino, por vezes, não passam de um conjunto de regras, procedimentos, convenções e estruturas de autoridade que controlam o modo como um grupo de pessoas irá agir para atingir um objetivo. Apesar de reconhecer a importância da existência de normas em determinados setores do contexto escolar, quando se trata do desenvolvimento de atividades propostas pelo professor, por exemplo, o autor não recomenda o uso de padronizações, pois isso impede que estudantes 
desenvolvam senso crítico, que compartilhem diferentes pontos de vista, e que constituam suas identidades na relação com o outro, por vezes, fazendo com que esses estudantes se sintam pressionados, ou que suas identidades de aprendizes não estejam sendo consideradas, conforme emerge em (7). Gee (2015), portanto, discute que conhecimentos que estudantes adquirem a partir de suas trajetórias devem ser considerados durante sua inserção em práticas de letramentos. Para o autor (2015) na inserção de estudantes em práticas de letramentos, principalmente em contextos digitais, o percurso de desenvolvimento de uma atividade por parte de um estudante é mais importante do que o produto final.

Os depoimentos dos membros indicam, ainda, que ao impedir que estudantes façam uso de diferentes conhecimentos e estratégias de aprendizagem, em uma prática de letramentos, a escola pode gerar a sensação de que esses estudantes são outsiders (GEE, 2001) dentro dessa prática, por não se afiliarem a um tipo ou outro de abordagem

metodológica, resultando, também, na desmotivação desses estudantes para o desenvolvimento de uma tarefa. Ao mencionarem "poder ter a liberdade de usar a tecnologia a teu favor é muito legal' e "tô fazendo esse slide e vou botar a Gretchen aqui” dão indícios de uma necessidade de usos de diferentes estratégias de aprendizagem com as quais, possivelmente, já se afiliam, como o uso de TD em práticas de letramentos.

\section{(In)acabamentos}

A partir das discussões realizadas neste estudo é possível discutir alguns aspectos que são importantes para refletir sobre o objetivo de compreender relações entre a comunicação oral com gamificação e identidades de estudantes em práticas de letramentos escolares na aprendizagem de inglês. Inicialmente, destaca-se a noção de que conflitos de identidades são constitutivos dos letramentos, pois é a partir da interação com as formas de falar, atuar, pensar, sentir e valorizar na interação com outros membros do discurso que um sujeito se torna letrado. É desses conflitos e interações que as identidades vão se deslocando e se moldando. Entretanto, o que emerge, essencialmente dos dados é que a prática de comunicação oral aliada à gamificação e aos usos das TD permitiu a amenização desses conflitos dentro do Clube de Inglês. Há de se considerar que a gamificação não necessariamente é dependente das TD para ser desenvolvida. Porém, optou-se pelo uso da plataforma Classcraft aliada aos artefatos presentes na escola com vistas a considerar os indícios das identidades dos membros do Clube de Inglês. 
Em relação à aprendizagem do inglês, nos posicionamos no sentido de que a gamificação, assim como qualquer outro artefato tecnológico, não pode se constituir como algo para remediar o sistema de ensino. Desse modo, apenas o uso da gamificação e das TD não garante a construção de sentidos de forma significativa aos membros do Clube. É necessário que esses elementos sejam incorporados a uma prática que também permita aos estudantes sentirem-se insiders a partir do uso de conhecimentos advindos de outras esferas, conforme ocorrido no Clube de Inglês, resultando em um aprimoramento da L2 por parte dos membros. Destaca-se a importância dessa mudança nas práticas de letramentos serem compreendidas como colaborativas, em que professores e estudantes constroem seus itinerários de aprendizagem, para que possam ser inseridos em práticas de forma significativa.

\section{REFERÊNCIAS}

BAKHTIN, M.; VOLOCHÍNOV, V. N. A Interação Verbal. In: Marxismo e Filosofia da Linguagem. Tradução de: Michel Lahud e Yara Frateschi Vieira. 12. ed. São Paulo: Hucitec, 2006. Cap. 6. p. 112-130.

BARTLETT, L. Situated identities and literacy pratices: to seem and to feel. Scripta, Belo Horizonte, v. 17, n. 32, p. 73-96, 2013. Disponível em: http://200.229.32.55/index.php/scripta/article/view/8742 Acesso em: 8 set. 2019.

BARTON, D.; HAMILTON, M. Literacy practices. In: Situated literacies: reading and writing in context. London: Routledge, 2000. p. 7-15.

BOGDAN, R.; BIKLEN, S. A escolha de um estudo. In: Investigação qualitativa em educação: uma introdução à teoria e aos métodos. Portugal: Porto, 1994, p. 85-88.

BUZATO, M. E. K. Por um enfoque pós-social fundamentado na Teoria Ator-Rede para os novos letramentos e a para a inclusão digital. Linguagem e Ensino, Pelotas, v.17, n.1, 2014. p. 25-60. Disponível em:

https://periodicos.ufpel.edu.br/ojs2/index.php/rle/article/viewFile/15338/9526. Acesso em: 23 dez. 2019.

DETERDING, C. S.; DIXON, D.; KHALED, R.; NACKE, L. From Game Design Elements to Gamefulness: Defining "Gamification". Proceedings of the 15th International Academic MindTrek Conference: Envisioning Future Media Environments, September 28-30, Tampere, Finland, 2011. Disponível em:

http://www.rolandhubscher.org/courses/hf765/readings/Deterding_2011.pdf. Acesso em: 29 mai. 2019.

FISCHER, A. Práticas de letramento acadêmico em um curso de Engenharia Têxtil: o caso dos relatórios e suas dimensões escondidas. Scripta, v. 15, n. 28, p. 37-58, 2011. 
FISCHER, A. A construção de letramentos na esfera acadêmica. 2007. Tese (Doutorado em Linguística) - Programa de Pós-Graduação em Linguística, Universidade Federal de Santa Catarina, Florianópolis, 2007.

GEE, J. P. The anti-education era: creating smarter students through digital learning. St. Martins Press, 2015. Ebook.

GEE, J. P. The new literacy studies: from socially situated to the work of the social. 2000. In: BARTON, D.; HAMILTON, M.; IVANIC, R. (Org.). Situated Literacies: reading and writing in context. London: Routledge, p. 180-196.

GEE, J. P. Reading as situated language: a sociocognitive perspective. Journal of adolescent \& adult literacy, v.8, n. 44, 2001. p. 136-151. Disponível em: http://jamespaulgee.com/pdfs/Reading\%20as\%20Situated\%20Language.pdf. Acesso em: 13 nov. 2019.

GOURLAY, L.; HAMILTON, M.; LEA, M. R. Textual practices in the new media digital landscape: messing with digital literacies. Research in Learning Technology. v. 21, 2014. p. 113. Disponível em: https://journal.alt.ac.uk/index.php/rlt/article/view/1442. Acesso em: 10 dez. 2019.

HALL, S. A identidade cultural na pós-modernidade. Trad. Tomaz Tadeu da Silva e Guacira Lopes Louro. 11. ed. Rio de Janeiro: DP\&A Editora, 2006.

JORDÃO, C. M. ILA - ILF - ILE - ILG: Quem dá conta? Revista Brasileira de Linguística Aplicada, Belo Horizonte, v. 14, n. 1, p. 13-40, 2014.

KLEIMAN, A. B. Trajetórias de acesso ao mundo da escrita: relevância das práticas não escolares de letramento para o letramento escolar. Perspectiva, Florianópolis, v. 28, n. 2, 2010. p. 375-400. Disponível em:

https://periodicos.ufsc.br/index.php/perspectiva/article/view/2175-795X.2010v28n2p375. Acesso em: 10 set. 2019.

LEFFA, V. J.; COSTA, A. C.; BEVILÁQUIA, A. F. Preferência dos estudantes na aprendizagem de línguas em três atividades do Moodle. Revista Brasileira de Linguística Aplicada, Belo Horizonte, v. 17, n.1, p. 113-136, 2017. Disponível em:

http://www.scielo.br/scielo.php?pid=S1984-63982017000100113\&script=sci_abstract\&tlng= pt. Acesso em: 12 jul. 2019.

LEFFA, V. J.; PINTO, C. M. Aprendizagem como vício: o uso de games na sala de aula. (Con)textos Linguísticos, v. 8, 2014. p. 358-378. Disponível em:

https://periodicos.ufes.br/contextoslinguisticos/article/view/8368. Acesso em: 23 out. 2019.

NORTON; B. Identity and language learning: extending the conversation. Toronto: Multilingual Matters, 2013.

NORTON; B. Identity, literacy, and English-language teaching. TESL Canada Journal, v. 28, n. 1, 2010. p. 1-13. Disponível em:

https://teslcanadajournal.ca/index.php/tesl/article/view/1057. Acesso em: 2 jan. 2020. 
STREET, B. Abordagens Alternativas ao Letramento e Desenvolvimento. Apresentado durante a Teleconferência Unesco Brasil sobre 'Letramento e Diversidade'. Londres, 2003.

VIANNA, C. A. D.; SITO, L.; VALSECHI, M. C.; PEREIRA, S. L. M. Do letramento aos letramentos: desafios na aproximação entre letramento acadêmico e letramento do professor. In: KLEIMAN, A. B.; ASSIS, J. A. (Orgs.). Significados e ressignificações do letramento: desdobramentos de uma perspectiva sociocultural sobre a escrita. Campinas, SP: Mercado de Letras, 2016. p. 27-59.

WENGER, E. Communities of practice: a brief introduction. 2004. Disponível em: $<$ http://wenger-trayner.com/introduction-to-communities-of-practice/>. Acesso em: 20 ago. 2019.

ZAVALA, V. Quem está dizendo isso?: letramento acadêmico, identidade e poder no ensino superior. In: VÓVIO, C.; SITO, L.; DE GRANDE, P. Letramentos: rupturas, deslocamentos e repercussões de pesquisas em linguística aplicada. Campinas, SP: Mercado de Letras, 2010. p. $71-95$

Recebido em 05/03/2020. Aceito em 10/06/2020. 